\title{
Chinese MAs' Evaluation in English Academic Writing: A Student-oriented Perspective
}

\author{
Jianping Xie \\ School of English Education, Guangdong University of Foreign Studies, Guangzhou, China
}

\begin{abstract}
Though it is well acknowledged in the academia that constructing authorial evaluation is important in English academic writing, L2 novice writers' views of and attitudes towards evaluation, which can help to understand their problematic evaluation demonstration in English academic writing, is generally underexplored. To address this gap, this study aims to investigate Chinese MA students' views of and attitudes towards evaluation in English academic writing, especially in the subgenre of literature review. To achieve this end, a semi-structured questionnaire survey among 174 Chinese MAs of Applied English Linguistics as well as interviews was conducted. Quantitative and qualitative data analyses show that the majority of the Chinese students have recognized the importance and necessity of evaluation in English academic writing, and their understandings of evaluation are generally accurate and in compliance with the institutionalized nature of academic writing. However, there are still quite many students possessing inadequate knowledge and underestimation of evaluation in English academic writing, which can partly be attributed to the general underplay of evaluation demonstration in the pedagogy of English academic writing and by supervisors as well. Explicit instruction on evaluation in the teaching of English academic writing as well as postgraduate supervisors' attention to and guidance in students' constructing authorial evaluation are therefore appealed for by the study.
\end{abstract}

Index Terms - evaluation, English academic writing, student perspective

\section{INTRODUCTION}

Evaluation is common in our everyday life, for example, teachers evaluate students' performance, readers evaluate the book content, or parents evaluate children's behavior. Though academic discourse was traditionally considered as a kind of discourse whose function was to transmit epistemic knowledge in a purely objective way, studies conducted in the past two decades such as Thompson and Ye (1991), Hunston (1994), Hyland (2000), Bondi (2008), Hood (2010), and Dueñas (2010) have unveiled the persuasive nature of academic writing in which evaluative meanings are ubiquitous and writers' authorial evaluations are strategically constructed to help convince readers of the validity and soundness of writers' epistemic knowledge claims and to "construct a dialogue and relations of solidarity with the reader" (Hyland \& Diani, 2009).

Despite the wide acknowledgement among scholars in the academia of the significance of evaluation in academic writing, especially in literature reviews which is the indispensable part in all academic genres (e.g., Hart, 1998; Feak \& Swales, 2009; Dawidowicz, 2010), novice writers' English academic writing are commonly found to be short of authorial evaluation (e.g., Feak \& Swales, 2009; Hood, 2004; Flowerdew, 2001) or filled with inappropriate evaluation (Xie, 2016). Given that L2 student writer's evaluating in English academic writing is a socio-cultural practice in essence which is subject to various personal and contextual factors, exploration of the possible factors for L2 student writers' evaluation performances can help to better understand their evaluating practice. However, in the extant literature, the majority of studies on L2 student writer's evaluation in English academic writing are text-oriented focusing on the features or patterns of authorial evaluation demonstrated in different academic texts such as argumentative essays (Hinkel, 1997; Wu \& Rubi, 2000), postgraduate thesis introductions (Sun, 2009), undergraduate thesis abstracts (Feng \& Zhou, 2007), etc., whereas research exploring the factors accounting for L2 student writers' evaluating practice away from the text itself are still rare.

In the context of mainland China, the group of postgraduates are growing fast in number each year, and English academic writing is a required skill for them to master given the lingua franca role of English in today's academic circle. There are a few studies investigating Chinese postgraduates' evaluation demonstration in English academic writing (e.g., Xie, 2016; Xu, 2007; Chen \& Li, 2019) which revealed some general patterns of their evaluation, however, the potential contributive factors are underexplored and research from the perspective of students themselves can hardly be found. How do Chinese MA students see and understand evaluation in English academic writing? To answer this question, this study, as part of a larger project on Chinese students' evaluation in English academic writing, intends to investigate Chinese MA students' actual views of and attitudes towards evaluation in English academic writing with a focus on the subgenre of literature review, hoping to achieve a better understanding of their evaluating practice in English academic writing and provide pedagogical implications for the teaching of English academic writing in China as well as other similar L2 contexts. 


\section{LITERATURE REVIEW}

Evaluation is a complicated concept which is not easy to define. Thompson and Ye (1991) interpreted evaluation as the conveying of the writer's view of the status of the information in his/her text, while Hyland and Diani (2009) regarded evaluation as a concept essentially concerned with the interpersonal meanings of language, that is, how the speaker/writer expresses his/her attitudes towards what he/she addresses and the material he/she addresses. The most often cited definition of evaluation was provided by Thompson and Hunston (2000) who defined evaluation as "a broad cover term for the expression of the speaker or writer's attitude or stance towards, viewpoint on, or feeling about the entities or propositions that he or she is talking about" (p. 5). This definition foregrounds that evaluation "has something to do with valuing and taking a position both to entities and to propositions" (Hood, 2010, p. 13). Basing on these definitions and oriented to academic discourse, this study defines evaluation in a broad sense as the writer's viewpoints on, emotions, attitudes, and positions towards the entities or propositions that are explicitly or implicitly encoded in the written academic texts.

Hyland and Diani (2009) highlighted the importance of evaluation in academic writing, saying that "among all the activities of the academy, what academics mainly do is evaluate" (p. 5). They also pointed out that evaluation performs three central functions in academic writing: 1) expressing the writer's opinion and thus reflects the value-system of the writer and their community; 2) helping to construct a dialogue and relations of solidarity between the writer and reader; and 3) assisting structure a text in expected ways. The importance of evaluation is especially obvious in the subgenre of literature reviews whose communicative purpose is to persuade the reader of the worth of the writer's study (Bunton, 2002; Kwan, 2006) and evaluation plays a critical role in achieving this aim (Hart, 1998; Feak \& Swales, 2009; Dawidowicz, 2010). For example, writers need to evaluate key works and identify core authors and relevant studies to create a research niche for and justify their own research in the literature review (Hart, 1998).

However, practitioners in undergraduate and graduate education have repeatedly voiced their concerns about the inadequate evaluation in novice writers' academic writing (e.g., Feak \& Swales, 2009; Hart, 1998; Hood, 2004, 2010). On the other hand, L2 novice student writers also perceive constructing appropriate evaluation in English academic writing as a highly challenging task (Hood, 2004). Analyzing from the perspective of journal editors, Flowerdew (2001) interviewed some journal editors and concluded that a lack of authorial voice characterizes L2 novice writers' academic writing and that the literature review is particularly problematic for them. Swales and Lindemann (2002) further listed some comments from professors on draft literature reviews written by graduate students or junior researchers as "merely a list" or "boringly chronological", which are "hard to know where the writer stand" and "need something more to evaluate and connect" (p. 107). As a matter of fact, a simple description or summary of previous studies appears to be a common phenomenon in novice writers' literature reviews, which are often "thinly disguised annotated bibliographies" (Hart, 1998, p. 1) rather than a "synthesized argument" (Xu, 2007, p. 13).

Among the many studies on L2 novice writers' evaluation in English academic writing, Xie's (2016) and Chen and Li's (2019) studies are particularly relevant to the present study. Through detailed textual analysis of Chinese MA students' evaluation in thesis literature reviews applying the appraisal framework, Xie (2016) found that these student writers, "in compliance with the institutionalized nature of academic writing" (p. 13), preferred evaluating the value of entities and propositions to judging other researchers or research behaviors or expressing personal emotions, and they encoded dominantly positive evaluation but stood neutrally when making references to other positions or voices. However, different from previous studies (e.g., Scollon, 1991; Hinkel, 1997) which suggested that Chinese students were prone to express evaluation indirectly in English academic writing, Xie revealed that the Chinese students "are not hesitant to express evaluation directly as the common stereotypical view would expect" (p.13) who encoded more explicit evaluations than implicit ones and they tended to be assertive in claim-making but often mitigated their assertiveness when evaluating. The author then argued that the Chinese students' preference for direct evaluation was a natural result of their change of evaluating "habit" over time given their greater exposure to English academic writing nowadays. Xie also mentioned that Chinese students' inadequate knowledge of evaluation due to its absence in instruction accounted for their problematic demonstration of evaluation. Chen and $\mathrm{Li}$ (2019) took a diachronic perspective and studied evaluation in Chinese MA thesis literature review chapters over two periods: 1990-2000 and 2005-2015. The findings revealed that the more recent student writers were "discursively more critical than their earlier counterparts" (p. 48). Similarly, the authors attributed this change to the recent relevant instruction on English academic writing offered by the relevant graduate program. Despite their inspiring findings, these two studies are still text-oriented, thus the authors could only resort to speculation when explaining the Chinese student writers' evaluation performance. How do present-day Chinese MA students actually view evaluation in English academic writing and do their understandings and knowledge of the matter explain their evaluation performance? These questions call for empirical research from the student's own perspective, which also specifically guided the present study.

\section{METHODS}

To elicit Chinese MA students' viewpoints of and attitudes towards evaluation in English academic writing, a questionnaire survey and follow-up interviews were conducted in the study.

\section{A. The Participants}


The questionnaires were distributed among 200 Year-3 Chinese MA students of Applied Linguistics in China. Altogether 174 valid questionnaires were retrieved and among the respondents, 15 were male and 159 were female, accounting for $8.6 \%$ and $91.4 \%$ respectively of the total number. This gender ratio is actually typical of the group of Chinese English-major students in China which is dominated by female students. The respondents were from 12 prestigious universities in China and the general information of them is provided in Table 1 below.

TABLE 1

GENERAL INFORMATION OF THE SURVEY RESPONDENTS

\begin{tabular}{cc|cccccc}
\hline \multicolumn{2}{c|}{\begin{tabular}{c}
\multicolumn{5}{c}{ Respondents } \\
$(\mathrm{N}=174)$
\end{tabular}} & \multicolumn{5}{c}{ Geographical distribution of the universities } \\
\hline $\mathrm{M}$ & $\mathrm{F}$ & Guangdong & Hunan & Beijing & Henan & Hong Kong & Shanghai \\
\hline 15 & 159 & GDUFS & HNU & BUAA & HENAU & PolyU & ECNU \\
$(8.6 \%)$ & $(91.4 \%)$ & JNU & & UIBE & & CUHK & \\
& & SYSU & & BISU & & & \\
& & & & & & & \\
\hline
\end{tabular}

The survey respondents were chosen out of two considerations: first, the English-major MA students generally have high English language proficiency which helps to rule out the potential variable of L2 writers' English language proficiency in evaluation demonstration in English academic writing. Second, English academic writing is a requirement for Chinese English-major MAs for fulfillment of MA degree whose theses are officially required to be written in English. The survey was administered at the beginning of their third academic year, which ensures that after two-year postgraduate study, the respondents generally have gained experiences in English academic writing and thus accumulated knowledge of English academic writing.

The interview participants were selected among the 174 survey respondents who indicated their willingness to take part in the follow-up interviews in the questionnaire. Following the principle of representativeness and accessibility, seven Year-3 MA students of Applied Linguistics were chosen from one university in Guangdong Province which is one of the most prestigious universities in English studies in China. The seven participants were all female students of a MA TESOL program in the university and they had taken one of the courses taught by the present researcher, which ensures the rapport between the researcher and the students.

\section{B. The Questionnaire}

Though this study is mainly concerned with Chinese MAs' views of and attitudes towards evaluation in English academic writing, their knowledge of academic writing and literature reviews in general can also shed light on their evaluating practice. Therefore, the questionnaire was designed to consist of four sections: Section One was about the students' demographic information such as name, gender, current institution, willingness to participate in the following interview, etc. Section Two aimed to elicit their views of academic writing, such as the importance, function and features of academic writing, their personal experiences in English academic writing, their assessments of their own abilities in English academic writing, and challenges and difficulties encountered in English academic writing. Section Three meant to generate respondents' understandings of the particular subgenre of literature review, such as its importance, content, generic structure, etc., Section Four was the major part which was designed to find out how the respondents view evaluation in academic writing, such as its importance in English academic writing and literature reviews, and their evaluating practices such as evaluation modes, evaluation types, objects of evaluation, and so on.

There were both close-ended questions (Example 1 below) and open-ended questions (Example 2) in the questionnaire, but the majority are mixed-type questions (Example 3). The questions were all in Chinese, the respondents' native language.

Example 1. Do you think it is necessary for academic writers to express personal evaluation (e.g., emotions, attitudes, opinions, positions) in English academic writing?
a). very necessary
b). necessary
c). neutral
d). unnecessary

Example 2. Could you briefly describe the ways in which you generally adopt or the steps you normally follow when writing a literature review?

Example 3. Do you think academic writers should directly or indirectly express their evaluations in English academic writing?
a). directly
b). indirectly

Why?

After the design of the questionnaire, the following measures were taken to ensure its validity and reliability: first, two professors who are familiar with the topic of this research were invited to read through the questions to assess whether the questions were pivoted on the topic under investigation, and to check for common errors like double-barreled, confusing, or leading questions. Afterwards a pilot study was administered among 30 Chinese MAs of Applied Linguistics for two times and Cronbach's Alpha (CA) was performed via SPSS to check the internal consistency of questions which generated a value of 0.87 , indicating a fairly good internal consistency of the responses. Finally, the questions were revised based on the information gleaned from the previous steps.

The actual questionnaire survey was carried out via the popular online survey platform "Wen Juan Xin" which is free to the public and the respondents completed and submitted the questionnaire through the online link generated by the 
platform.

\section{The Interview}

One-to-one and face-to-face in-depth interviews were carried out with the seven participants after they had completed and submitted their MA theses, through which they had gained more and deeper understandings and experiences of English academic writing. Since the interview was meant to generate more detailed ideas and thoughts from the students about evaluation in English academic writing, the interview guide also followed the three themes of the questionnaire survey: academic writing, literature review and evaluation in English academic writing. In the interview, the participants were first invited to elaborate on their responses in the questionnaire survey. Then the interview centered on their evaluating practice in their MA thesis so as to entice more detailed thoughts from them basing on their most recent thesis writing experiences.

The interviews were also semi-structured, as which can offer the researcher more organized and focused access to the interviewees' opinions while at the same time giving the interviewees a certain degree of power and control over the course of interviews (Nunan \& David, 1992). That is to say, even though the interviews generally followed the interview guide, the specific forms and order of the questions were varied and tailored for the different student participants. All interviews were undertaken in Chinese and observed the principles of "rapport" and "neutrality" (Patton, 1990) in which the participants' voices were fully listened to and they were encouraged to share with frankness and comfort. Each interview took about one hour and was recorded with the permission of the participants.

\section{Data Analysis}

Data from the questionnaire survey and interviews were analyzed in different ways. The platform "Wen Juan Xing" through which the questionnaire survey was conducted can automatically generate statistical data according to the students' responses. Since the survey was exploratory in nature, a modest statistical analysis basing on the data generated by the platform was adopted in the study.

The interviews were transcribed verbatim into Chinese and then content analysis of the transcriptions was carried out according to the three broad themes (namely academic writing, literature reviews, and evaluation in English academic writing) on which the interview questions were based as discussed earlier. The data analysis involved synthesis and categorization to bring about enriched information on the students' knowledge of and attitudes towards evaluation in English academic writing, especially those that could shed light on their actual evaluation performance.

\section{FINDINGS AND DISCUSSION}

\section{A. Chinese MAs' Views of English Academic Writing}

For this section, the Chinese MA students were asked about their (1) experiences in English academic writing; (2) views on the importance of English academic writing; and (3) their assessments of their own English academic writing abilities.

According to the survey, the Chinese MA students' experiences in English academic writing mainly come from course paper and research proposal writing. Given that the respondents are Year-3 postgraduates, they are expected to have accumulated experiences in writing course paper which is the major assessment form for postgraduates in China. Actually, by the time of the survey, over half of the students $(39.9 \%+10.2 \%)$ (see Table 2 ) have written more than six course papers during the past two-year study, and 66\% of them have finished the MA research proposal as different university has different schedule for submitting the research proposal. It is worth noticing that the dominant majority $(85.6 \%)$ do not have any experiences in publishing research articles on English-medium journals. One out of the seven students in the interview had published one research article on a domestic journal, but when being asked why she had not tried to publish an English research article, she said "Publishing an English research article is beyond my current capacity as a master student, because it is too demanding for us given our English language proficiency and research abilities." However, as Table 3 shows, $73.0 \%$ of the Chinese students consider English academic writing as very important, and $23 \%$ of them think it important, indicating that they have generally recognized the important role of English academic writing for their postgraduate study and future career. For example, one student said that "English academic writing is very very important nowadays because most of the academic knowledge are transmitted in English." Despite their general recognition of the importance of English academic writing, most of the students (62.1\%) assess their abilities of English academic writing as average, and some consider their English academic writing skill as poor $(20 \%)$ or even very poor $(2.9 \%)$, with only $14.9 \%$ of the students confidently labelling their abilities as good. This implies that English academic writing is still a very challenging task for the average Chinese MA students. When invited to specify the aspects in need of improvement in English academic writing, the most frequently mentioned aspect is logic argumentation which is "hard to build over the extended segments in academic texts", and another one is surprisingly language especially vocabulary: "I feel my academic vocabulary is not professional and large enough and I have to repeat the same sentence structure and limited number of words again and again, thus turning my writing into a dull piece." This implicates that the teaching of English academic writing should give more weight to the instruction on argumentation and academic vocabulary because what the students find challenging is what needs to be focused on in the instruction. 
TABLE 2.

CHINESE MAS' EXPERIENCES OF ENGLISH ACADEMIC WRITING

\begin{tabular}{|l|llll|}
\hline Type & 0 & $1-5$ & $6-10$ & Over 11 \\
\hline Quantity & & $49.9 \%$ & $39.9 \%$ & $10.2 \%$ \\
\hline Course paper & $0 \%$ & $12.1 \%$ & $2.3 \%$ & $0 \%$ \\
Research article & $85.6 \%$ & $66.0 \%$ & $0.7 \%$ & $0 \%$ \\
Research proposal & $33.3 \%$ & $14.4 \%$ & $1.7 \%$ & $0 \%$ \\
Grant project & $83.9 \%$ & & \\
\hline
\end{tabular}

TABLE 3.

CHINESE MAs' VIEWS OF ENGLISH ACADEMIC WRITING

\begin{tabular}{|c|c|c|}
\hline \multicolumn{3}{|c|}{ Importance of English academic writing } \\
\hline Very Important: $127(73.0 \%)$ & Important: $40(23.0 \%)$ & \\
\hline Neutral: $6(3.5 \%)$ & Unimportant: $1(0.5 \%)$ & \\
\hline \multicolumn{3}{|c|}{ Ability in English academic writing } \\
\hline Excellent: $0(0.0 \%)$ & Good: $26(14.9 \%)$ & Fair: $108(62.1 \%)$ \\
\hline Poor: $35(20.1 \%)$ & Very poor: $5(2.9 \%)$ & \\
\hline
\end{tabular}

When asked to rank the different parts in English academic writing in terms of difficulty, the Chinese students rated literature review as the most difficult, followed by methodology, results, discussion, abstract, introduction, and finally conclusion (see Figure 1). It is within expectation that literature review is viewed as one of the most challenging subgenre in English academic writing since in the literature review the writer not only needs to display his/her comprehensive knowledge of a particular area, but also to develop that knowledge through sound reasoning and good maneuver of evaluation. Moreover, the writer also needs to weave a strong argument for his/her novel study and certify his/her contribution to the disciplinary community. For a L2 novice academic writer, all these are effortful not only in terms of epistemic knowledge but also in terms of academic writing skill. Some students also mentioned that building coherence in literature review instead of "patching the studies together randomly" is also very demanding for them.

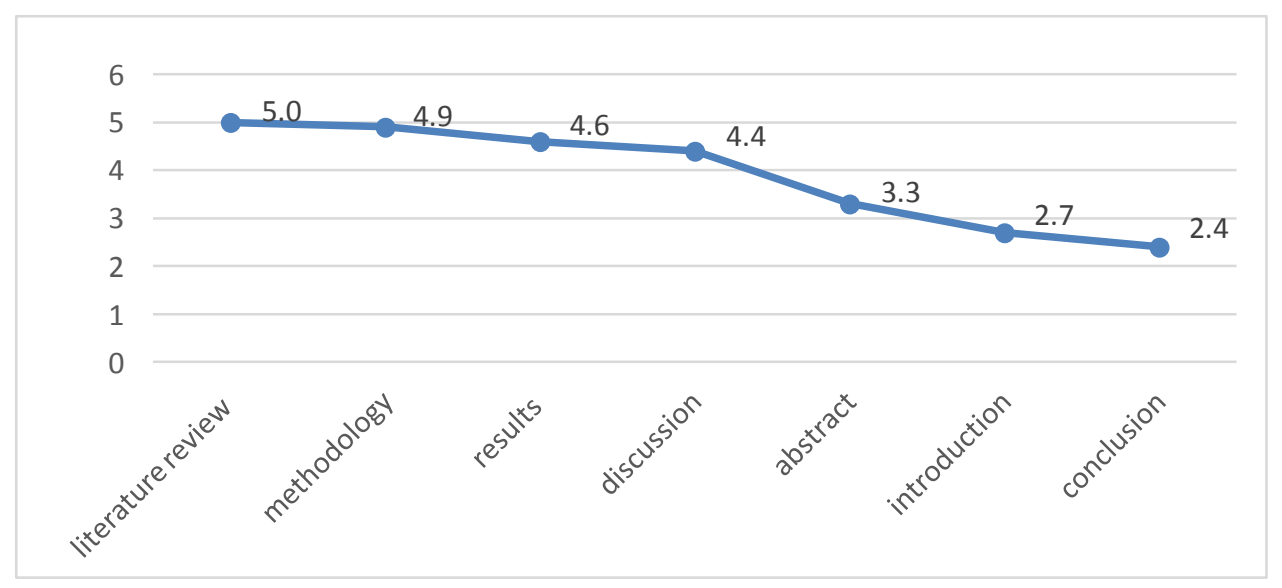

Figure 1. Ranking of different sections in terms of difficulty

\section{B. Chinese MAs' Views of Literature Reviews}

As discussed above, literature review is the subgenre that most Chinese MA students consider the most difficult, this section will present their understandings of literature reviews so as to shed light on their evaluating practice in literature reviews.

Among the 174 survey respondents, 109 (62.6\%) view literature review as very important, 57 (32.8\%) consider it important, with only eight students $(4.6 \%)$ thinking it neutral and none viewing it unimportant. Therefore we can say that the Chinese MAs have generally recognized the importance of literature reviews in academic writing. For the content of literature review, there was a multiple-choice question in the survey which required the students to tell the "generic moves" which academic writers should include in literature reviews and the results are presented in Figure 2. We can see that $92.0 \%$ of the students consider "analyzing and finding out the research gap in the literature" as essential in the literature review, and $67.2 \%$ consider "arguing for the centrality of one's research topic" and $66.1 \%$ consider "arguing for the worth of one's own study" as essential. These three aspects actually correspond to the major moves of literature review proposed by Kwan (2006), indicating the majority of the Chinese MAs have formed a correct understanding of the content of literature reviews. 


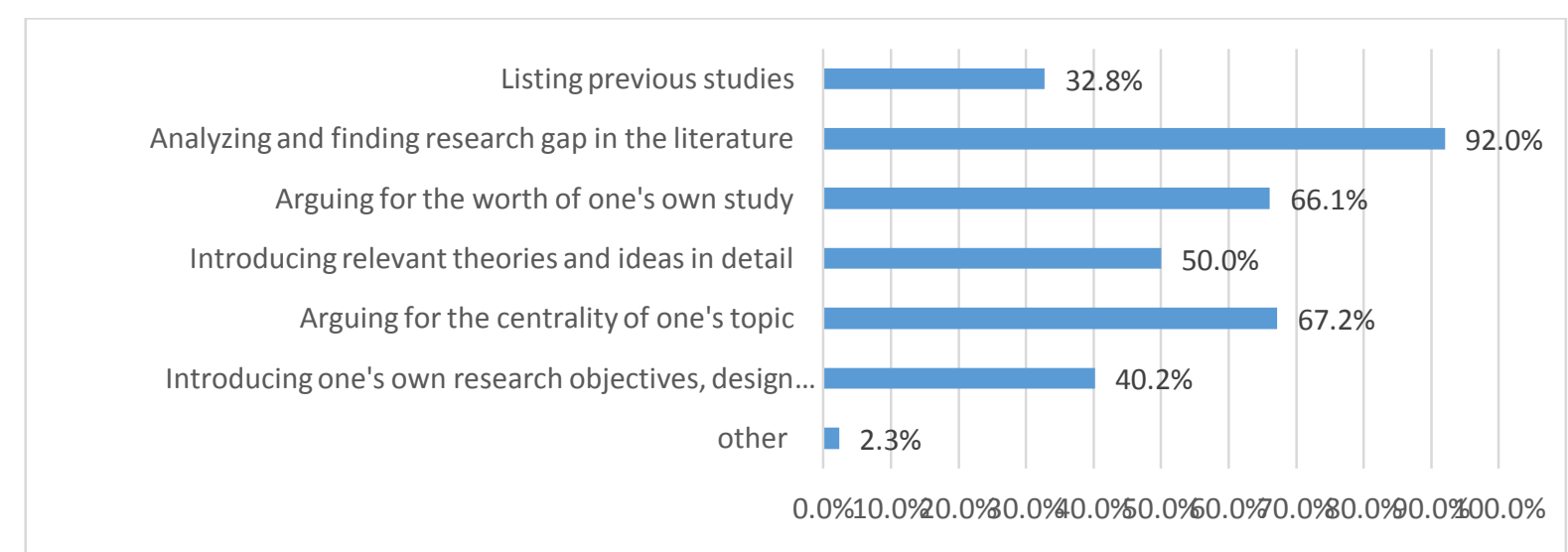

Figure 2. Chinese MAs' understandings of the content of literature reviews

However, there are still quite a number of students who seem to hold an imprecise comprehension of literature reviews which may account for some of the problematic practice in their literature review writing. For example, half of the survey respondents (see Figure 2) chose "introducing relevant theories and ideas in detail" and $32.8 \%$ of them selected "listing previous studies", which can explain why quite a number of Chinese MAs turned their thesis literature reviews into pure descriptions of relevant theories and ideas in full details and gave a simple listing of previous studies without any synthesis or analysis as pointed by Xie (2016). As a matter of fact, some Chinese students consider the literature review as a mere description and summary of previous studies and theories, holding that writing literature review is to "list previous studies one by one, describe relevant theories and their development in details, and summarize the literature in the end" and thus making their literature reviews "overly descriptive" (Xie, 2016, p.13). It also deserves our attention that many Chinese MAs have developed a rigid pattern in organizing the literature: "I first review the foreign studies, then the domestic ones, and finally summarize the whole literature". Though we cannot say that this pattern is wrong or inappropriate, more diversified overall structure deployment tailored for different research topics can and should be encouraged and taught in the teaching of literature review writing.

\section{Chinese MAs'Views of Evaluation in English Academic Writing}

\section{General views and attitudes}

This section presents Chinese MAs views of and attitudes towards evaluation in English academic writing, especially in literature reviews.

From Table 4, we can see that $21.3 \%$ of the Chinese students consider evaluation as very necessary in English academic writing and $43.1 \%$ of them consider it necessary. However, there are $29.9 \%$ of them standing neutrally towards the necessity of evaluation and $5.7 \%$ think evaluation unnecessary. This shows that though the majority of the postgraduates have realized the necessity of evaluation in English academic writing, there are still plenty of students have not developed such awareness. As for the subgenre of literature reviews, despite the wide acknowledgement of the importance of evaluation in literature reviews in the academia as discussed earlier, over $30 \%$ of the students $(27.0 \%+6.3 \%)$ are still insensible of the importance of evaluation. Nevertheless, the majority of the students think expressing authorial evaluation as challenging in English academic writing with $10.3 \%$ of them view it as very difficult and $53.5 \%$ as difficult. This finding is in consistence with what Hood (2004) have found about novice L2 student writers in Hong Kong.

TABLE 4.

CHINESE MAs' VIEWS OF EVALUATION IN ENGLISH ACADEMIC WRITING

\begin{tabular}{|c|c|c|}
\hline \multicolumn{3}{|c|}{ Necessity of evaluation in English academic writing } \\
\hline Very necessary: $37(21.3 \%)$ & \multicolumn{2}{|c|}{ Necessary: $75(43.1 \%)$} \\
\hline Neutral: $52(29.9 \%)$ & \multicolumn{2}{|c|}{$\begin{array}{l}\text { Necessary: } 75(43.1 \%) \\
\text { Unnecessary: } 10(5.7 \%)\end{array}$} \\
\hline \multicolumn{3}{|c|}{ Difficulty of expressing evaluation in English academic writing } \\
\hline Very difficult: $18(10.3 \%)$ & \multicolumn{2}{|c|}{ Difficult: $93(53.5 \%)$} \\
\hline Neutral: $53(30.5 \%)$ & \multicolumn{2}{|c|}{ Not difficult: $10(5.7 \%)$} \\
\hline \multicolumn{3}{|c|}{ Importance of evaluation in literature review } \\
\hline Very important: $24(13.8 \%)$ & \multicolumn{2}{|c|}{ Important: $92(52.9 \%)$} \\
\hline Neutral: $47(27.0 \%)$ & \multicolumn{2}{|c|}{ Unimportant: $11(6.3 \%)$} \\
\hline \multicolumn{3}{|c|}{ Evaluation: Direct or indirect? } \\
\hline Direct: $87(50.0 \%)$ & Indirect: $82(47.1 \%)$ & Other: $5(2.9 \%)$ \\
\hline \multicolumn{3}{|c|}{ Evaluation: Positive or negative? } \\
\hline Positive: $107(61.5 \%)$ & Negative: $13(7.5 \%)$ & Other: $54(31.0 \%)$ \\
\hline
\end{tabular}

In terms of the mode of evaluation, Xie (2016) found that Chinese students were not hesitant in expressing evaluation directly in English academic writing. In the survey of this study, it is shown that half of the students (50.0\%) think academic writers should express evaluation directly while nearly another half $(47.1 \%)$ hold the opposite opinion. In the interview, students who agreed with the former explained that "Academic writing, which is different from other types of 
writing, is mainly concerned about information and knowledge, so as long as my evaluation is objective and soundly based, why can't I express it directly?" The other students who considered indirect evaluation as more preferable said: "I tend to evaluate implicitly to be safe, because I feel not very confident given that I am not as knowledgeable as those established scholars." Therefore, it would not be wise to label the Chinese students either as direct or indirect in the case of expressing evaluation given the huge diversity existent among this group just like any other cultural groups around the world. With regard to the polarity of evaluation, the majority of the students $(61.5 \%)$ think academic writers should encode positive evaluation in academic writing and only $7.5 \%$ of them deem negative evaluation to be the recommendable polarity. This is consistent with Xie's (2016) finding that positive evaluation dominates Chinese students' English academic writing, which is within expectation as building solidarity with the academic community is highly valued in the academia (Hyland, 2000). It is also worth mentioning that $31 \%$ of the Chinese MAs chose the "Other" option, thinking that "Either to encode positive or negative evaluation depends on the specific situation, and academic writers should evaluate objectively basing on reasonable and comprehensive judgement without considering whether it is positive or negative evaluation for its own sake."

When it comes to the object of evaluation, Chinese MAs' views and practices seem even more varied. As Table 5 shows, "the status quo of relevant fields" seems to be the most common object of evaluation among the Chinese students, with $42.0 \%$ of them often evaluate the status quo of extant literature and $19.5 \%$ of them always do so. "Other studies and opinions", "research topics and themes", and "relevant theories and analytical frameworks" are the following three aspects that are commonly targeted by the Chinese MAs with students assessing the three aspects regularly accounting for $36.8 \%, 34.5 \%$, and $33.3 \%$ respectively of the total number. Chinese students appraise "other scholars and their achievements" as well as "one's own study" less commonly with $28.7 \%$ of them often evaluate other scholars and $27.6 \%$ often gauge their own studies. "Methodology and methods" is the least popular object of evaluation among the students with $21.8 \%$ of them evaluate this methodological aspect occasionally and $11.6 \%$ never evaluate this aspect. This is again within the researcher's expectation because evaluating methodology is epistemically exacting and master students in general are cognitively less equipped than $\mathrm{PhD}$ students or established scholars.

TABLE 5.

CHINESE MAs' OBJECTS OF EVALUATION

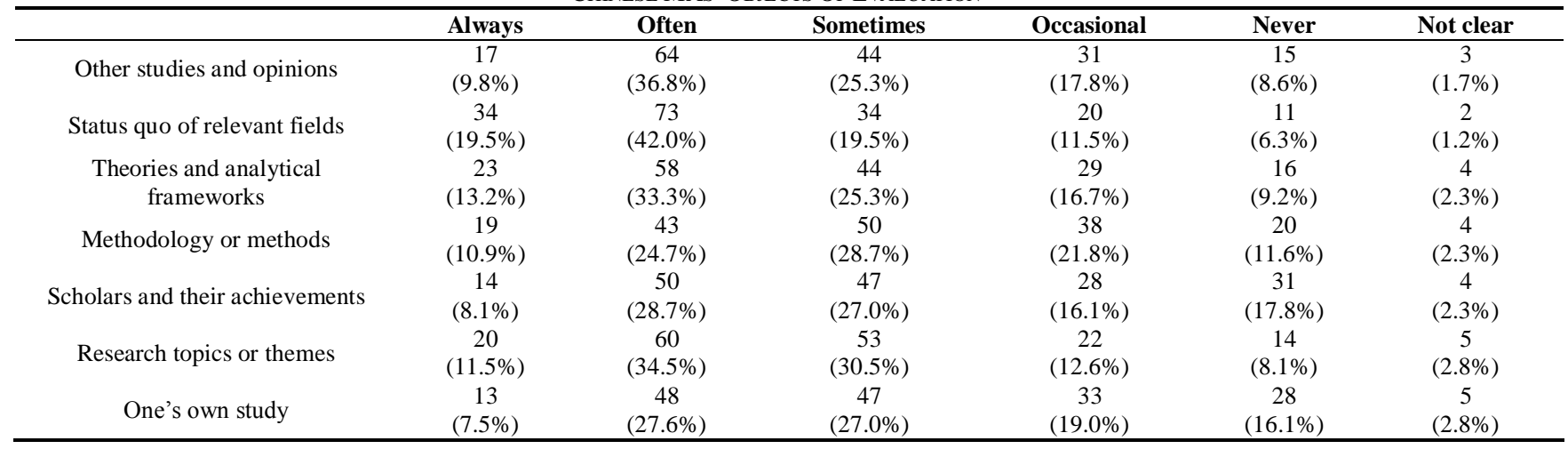

Regarding the evaluation type, the majority of the postgraduate students (89.7\%) hold evaluation in English academic writing should involve the social value of research entities and activities (see Figure 3), this view is compliant with the institutionalized nature of academic writing. However, only $38.5 \%$ of them deem demonstration of personal evaluative stances towards research propositions necessary, which to some extent explains the phenomenon that when referring to other propositions, Chinese students tend to stand neutrally towards the cited information as discovered by Xie (2016). It should be noted that there are $42.5 \%$ of the students believing that ethical judgement of other researchers or behaviors is appropriate for academic evaluation. This belief, however, is against the institutionalized nature of academic writing as which is less about appraisement of person and behavior but more concerned with the social value and significance of research entities and propositions. 


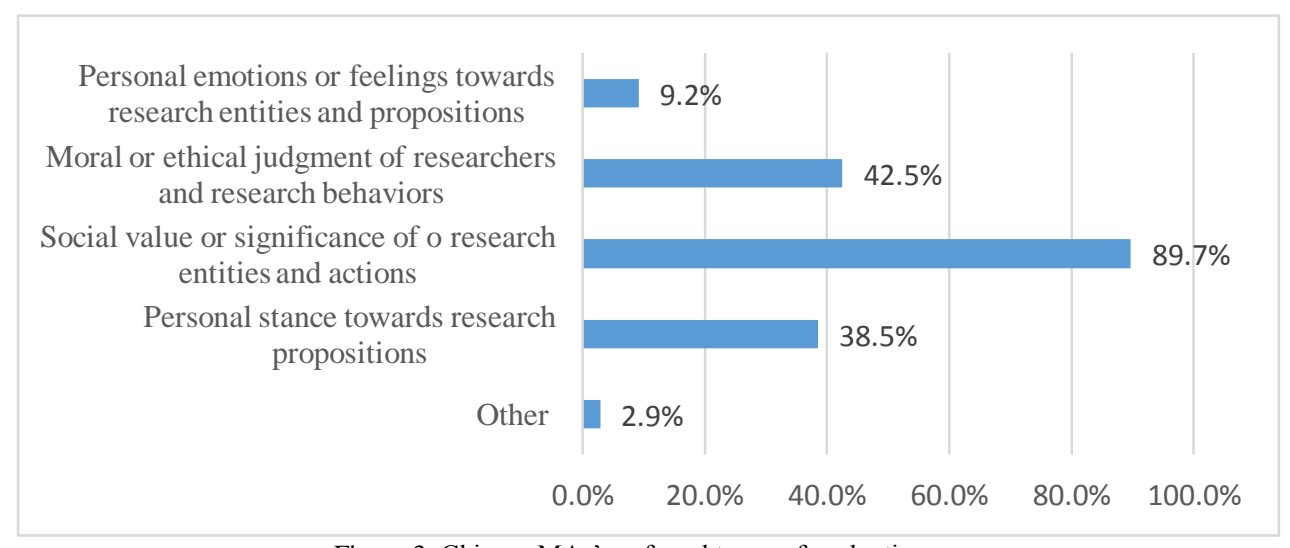

Figure 3. Chinese MAs' preferred types of evaluation

With regard to the assertiveness of evaluation, over half of the students indicated that they would soften the tone when making evaluations, because "I am not confident in expressing personal opinions in academic writing", "Softening the tone can make myself less vulnerable to criticism", "I soften the tone to show my modesty", "I soften the tone to avoid sounding too absolute since there are always exceptions". In contrast, there are also many students offering the adverse reply who would not soften their tone because "this will make my evaluation appear unobjective and unprofessional", "we should be crystal clear when making claims", "uncertainty will lead readers to doubt the reliability of my claims", or "academic writing should be precise without vagueness", etc. These views partly explain the coexistence of assertiveness and mitigation in Chinese MAs' literature reviews as found in the literature (e.g., Xie, 2016).

2. Possible influencing factors

Instruction has been considered as an influencing factor for Chinese students' evaluating practice in English academic writing (e.g., Xie, 2016; Chen \& Li, 2019). This study found that there is a lack of sufficient instruction or guidance on evaluation for the Chinese MA students. As Table 6 shows, 77.6\% of the survey respondents reported they had not received any explicit instruction on how to construct effective authorial evaluation in English academic writing. As a matter of fact, according to the present researcher's informal survey, relevant instruction on English academic writing for postgraduates in China mainly focuses on the broad format matter, such as the overall structure of a research paper, styles to follow in in-text citation and reference list, and technical means to reach resources, whereas content-based instruction such as argumentation deployment and evaluation demonstration are generally neglected. In addition, supervisors also play a vital role in guiding postgraduates to the conventionalized practice of English academic writing. However, only $29.3 \%$ of the students reported they had received guidance on evaluation demonstration in English academic writing from their supervisors. In the interviews, the students also mentioned that their supervisors mainly provided guidance in the general research design and overall structuring of the thesis, and seldom or even never offered any feedback about evaluation during the whole thesis writing process. Such common neglect from the course instructors and supervisors contribute to the novice Chinese students' scant knowledge of evaluation and consequently their problematic demonstration of evaluation, because it is hard for the students to intuitively appreciate the means of constructing effective authorial evaluation by themselves.

TABLE 6.

INSTRUCTION ON EVALUATION

\begin{tabular}{l} 
INSTRUCTION ON EVALUATION \\
\hline Any instruction on evaluation from the course? \\
$\begin{array}{l}\text { Yes: } 39(22.4 \%) \\
\text { No: } 135(77.6 \%)\end{array}$ \\
$\begin{array}{l}\text { Any guidance on evaluation from the supervisor? } \\
\text { Yes: } 51(29.3 \%)\end{array}$ \\
\hline
\end{tabular}

In addition to instruction, Chinese students' self-awareness of their academic status may be another reason for some of their evaluating performance. Over half of the students said they would think of their novice academic status when evaluating in academic writing, especially when they were trying to voice their own opinions, raise opposing opinions, or making negative evaluations. Considerations for such awareness are diversified: "I would think of my novice status in the academic field and adjust my evaluation to make it more credible", "I am worried that the professors in my committee will disapprove", or "I am not confident in myself as I am nobody in the field, unlike those experts". On the other hand, many students said they would not consider their academic status when evaluating in academic writing because "We should not consider the evaluator's academic status as a criterion for judging the validity of the evaluation"; "Academic evaluation is about the academic community in general and should not be taken personally as academic progress can only be achieved through open discussion, questioning and criticism"; or "My teachers are the only readers of my academic writing, so I can be honest and candid with them when making evaluation."

\section{CONCLUSION}


This study, from the students' perspective, examined Chinese MA students' understandings of evaluation in English academic writing through questionnaire survey and interviews. Results of this study showed that the majority of the Chinese students have recognized the importance of evaluation in English academic writing, and their understandings of evaluation in terms of type, mode, polarity, content and objects are generally accurate and in compliance with the institutionalized nature of academic writing. However, there are still quite many Chinese students possessing inadequate knowledge and underestimation of evaluation in English academic writing, which can explain some of the problematic demonstration of evaluation by the Chinese students as reported in the literature. Insufficient guidance from the relevant instruction and supervisors on evaluation is also revealed in this study, which is partly responsible for students' inadequate knowledge of evaluation. Therefore, this study calls for explicit instruction on evaluation demonstration in the teaching of English academic writing as well as postgraduate supervisor's attention to and necessary guidance in students' constructing authorial evaluation in English academic writing.

This study focused on the L2 students' views of and attitudes towards evaluation in English academic writing and unveiled some possible contributive factors for the student writers' problematic performance of evaluation in English academic writing. Given that evaluating is a socio-cultural practice, more complicated objective and subjective factors are at play in the matter. Therefore, process-oriented perspective or teachers'/supervisors' angles are recommended for future studies so as to engender more enriched findings on the topic.

\section{ACKNOWLEDGEMENTS}

This work was supported by Guangdong Planning Office of Philosophy and Social Science, China under 2015 Project Grant [GD15YWW04]; Guangdong University of Foreign Studies, China under 2017 Teaching Research Project Grant [GWJY2017004], and Guangdong University of Foreign Studies, China under 2019 Postgraduate Education Innovative Project Grant [19GWYJSCX-09].

\section{REFERENCES}

[1] Bondi, M. (2008). Emphatics in academic discourse: Integrating corpus and discourse tools in the study of cross-disciplinary variation. In A. Ädel \& R. Reppen (Eds.), Corpora and discourse: The challenges of different settings (pp.31-56). Amsterdam/Philadelphia: John Benjamins Publishing Company.

[2] Bunton, D. (2002). Generic moves in PhD theses introductions. In J. Flowerdew (Ed.), Academic discourse (pp. 57-75). Pearson, UK: Pearson Education Limited.

[3] Chen, X., \& Li, M. (2019). Chinese learner writers' niche establishment in the Literature Review chapter of theses: A diachronic perspective. Journal of English for Academic Purposes, 39, 48-58.

[4] Dawidowicz, P. (2010). Literature reviews made easy: A quick guide to success. NC: Information Age Publishing Incorporation.

[5] Dueñas, P. M. (2010). Attitude markers in business management research articles: A cross-cultural corpus-driven approach. International Journal of Applied Linguistics, 20(1), 50-72.

[6] Feak, C. B., \& Swales, J. M. (2009). Telling a research story: Writing a literature review. Michigan: The University of Michigan Press.

[7] Feng, Y., \& Zhou, R. (2007). Using hedges in academic writings: A comparative study. Foreign Language and Literature Studies, 2, 108-112.

[8] Flowerdew, J. (2001). Attitudes of journal editors to nonnative speaker contributions. TESOL Quarterly, 35(1), $121-150$.

[9] Hart, C. (1998). Doing a literature review. London: SAGE Publications Ltd.

[10] Hinkel, E. (1997). Indirectness in Ll and L2 academic writing. Journal of Pragmatics, 27, 361-386.

[11] Hood, S. (2004). Appraising research: Taking a stance in academic writing. Unpublished doctoral dissertation, University of Technology, Sydney, Australia.

[12] Hood, S. (2010). Appraising research: Evaluation in academic writing. Basingstoke, UK: Palgrave Macmillan.

[13] Hunston, S. (1994). Evaluation and organization in a sample of written academic discourse. In M. Coulthard (Ed.) Advances in written text analysis (pp.191-218). London: Routledge.

[14] Hyland, K. (2000). Disciplinary discourse: Social interactions in academic writing. UK: Pearson Education Limited.

[15] Hyland, K., \& Diani, G. (2009). Introduction: Academic evaluation and review genres. In K. Hyland \& G. Diani (Eds.), Academic evaluation: Review genres in university settings. Basingstoke, UK: Palgrave Macmillan.

[16] Kwan, B. S. (2006). The schematic structure of literature reviews in doctoral theses of applied linguistics. English for specific purposes, 25(1), 30-55.

[17] Nunan, D., \& David, N. (1992). Research methods in language learning. NY: Cambridge University Press.

[18] Patton, M. Q. (1990). Qualitative evaluation and research methods. California: SAGE Publications, inc.

[19] Scollon, R. (1991). Eight legs and one elbow: Stance and structure in Chinese English composition. Paper presented at International Reading Association, Second North American Conference on Adult and Adolescent Literacy, Banff, Canada.

[20] Sun, Y. H. (2009). An analysis of citations used in introductions of Chinese M.A. thesis. Foreign Language Education, 30 (1), 53-58.

[21] Swales, J. M., \& Lindemann, S. (2002). Teaching the Literature Review to international graduate students. In A. M. Johns (Ed.), Genre in the classroom (pp. 105-119). NJ: Lawrence Erlbaum Associates, Inc.

[22] Thompson, G., \& Ye, Y. (1991). Evaluation of the reporting verbs used in academic papers. Applied Linguistics, 12(4), 365-382. 
[23] Thompson, G., \& Hunston, S. (2000). Evaluation: An introduction. In S. Hunston \& G. Thompson (Eds.), Evaluation in text: Authorial stance and the construction of discourse (pp. 1-27). Oxford: Oxford University Press.

[24] Wu, S. Y., \& Rubin, D. L. (2000). Evaluating the impact of collectivism and individualism on argumentative writing by Chinese and North American college students author. Research in the Teaching of English, 35(2), 148-178.

[25] Xie, J. P. (2016). Direct or indirect? Critical or uncritical? Evaluation in Chinese English-major MA thesis literature reviews. Journal of English for Academic Purposes, 23, 1-15.

[26] Xu, H. (2007). A corpus-based study of authorial stance markers in academic research discourse by Chinese advanced EFL writers. Hefei, China: Hefei University of Technology Press.

Jianping Xie is an associate professor at School of English Education, Guangdong University of Foreign Studies, China. Her current research areas include English academic writing, discourse analysis, and English language teaching. 